\title{
Exploring Our Past to Prepare for Our Future
}

\author{
Charlie Andrews, NODA President, 2004-2007
}

As the National Orientation Directors Association (NODA) celebrates 30 years since our incorporation, we have dedicated this edition of the Journal to reflect on our history and some of the highlights that have shaped both the association and our profession. As an introduction, I would like to offer my perspective on the concept that knowing where you came from provides a context for where you are headed.

Over the years, NODA has served as a resource for those who coordinate orientation and transition programs. What began as an annual gathering of orientation professionals has evolved into a professional association that offers a variety of publications, networks, conferences, a new professionals' institute, and access to best practices. In recent history, that has included providing our members with resources on topics including the impact of orientation on retention, the increase in parental involvement, new advances in technology, transfer student issues and programs, and supporting the first-year experience beyond orientation. In addition, the leadership of NODA has also focused our efforts on ways to continue providing these types of resources to our membership.

For the past several years, a great deal of time and energy has been dedicated to the establishment of a permanent home office and hiring NODA's first Executive Director. Taking the lead from other professional associations, we recognized these goals as vital to our desire to centralize our operations and bring the association to the next level. Thanks to the partnership we have developed with the University of Minnesota-Twin Cities and a successful Executive Director search process, I am pleased to report that both of these have become a reality.

So what does that mean for NODA's future?

As we look back at the first 30 years of NODA as an official association, let us also consider what NODA might look like 30 years from now. The Board of Directors has had a number of conversations about where NODA is headed and the new initiatives we hope to explore. As we take advantage of our new home office location and our first ever full-time staff member, I envision NODA with some of the following resources and initiatives by the year 2037:

- Increased scholarly works and new publications

- Centralized procedures in the home office and increased efficiency

- Educational grants

Charlie Andrews (andrewsc@fiu.edu) is the Director of Campus Life \& Orientation at Florida International University. 
- New partnerships with other professional associations and increased exposure within those associations

- Strategic partnerships with companies that provide services to members

- Additional regional activities and workshops

- Professional development institutes for advancing and established professionals

- Increased use of technology and the Web to provide resources to members

- Development of on-campus consulting services

- Enhanced programming for regional and annual conferences

These are just a few of the possibilities that have been discussed as we enter this next phase in the history of NODA. As we move beyond the 30 year mark, there is so much to be proud of and even more to anticipate. For those who have been a part of NODA history, you should be thanked for the role you played in getting the association to the place we are now. For both NODA veterans and those who are new to NODA, I hope you find a way to remain an active part of helping us lay the groundwork for NODA's future and ask yourself, where you think NODA will be in the year 2037? 